\title{
Modulation of Cellular Immunity in Medical Students
}

\author{
Janice K. Kiecolt-Glaser, ${ }^{1,5}$ Ronald Glaser, ${ }^{2,3}$ \\ Eric C. Strain, ${ }^{1}$ Julie C. Stout, ${ }^{2}$ Kathleen L. Tarr, ${ }^{2}$ \\ Jane E. Holliday, ${ }^{2}$ and Carl E. Speicher ${ }^{4}$ \\ Accepted for publication: December 8, 1984
}

\begin{abstract}
This study assessed the psychosocial modulation of cellular immunity in 34 medical-student volunteers. The first blood sample was obtained 1 month before examinations, and the second on the day of examinations. There were significant declines in the percentage of helper/inducer T-lymphocytes, in the helper/inducer-suppressor/cytotoxic-cell ratio, and in natural killer-cell activity in the blood samples obtained on the day of examinations. Half of the subjects were randomly assigned to a relaxation group which met between sample points; the frequency of relaxation practice was a significant predictor of the percentages of helper/inducer cells in the examination sample. Three biochemical nutritional assays (albumin, transferrin, and total iron-binding protein) were within normal limits on both samples. Data from the Brief Symptom Inventory showed significantly increased global self-rated distress associated with examinations in the no-intervention group, compared to nonsignificant change in the relaxation group. Clinical and theoretical implications are discussed.
\end{abstract}

KEY WORDS: stress; psychoimmunology; relaxation; cellular immunity.

This study was supported in part by funds from the State of Ohio Department of Mental Health, the Bremer Foundation, and the Samuel J. Roessler Fund and by Ohio State University Comprehensive Cancer Center Grant CA-16058-09 from the National Cancer Institute, National Institutes of Health.

'Department of Psychiatry, Ohio State University College of Medicine, Columbus, Ohio 43210.

${ }^{2}$ Department of Medical Microbiology and Immunology, Ohio State University College of Medicine, Columbus, Ohio 43210.

${ }^{3}$ Comprehensive Cancer Center, Ohio State University College of Medicine, Columbus, Ohio 43210.

${ }^{4}$ Department of Pathology, Ohio State University College of Medicine, Columbus, Ohio 43210.

${ }^{5}$ To whom correspondence should be addressed at Department of Psychiatry, Ohio State University College of Medicine, 473 West 12th Avenue, Columbus, Ohio 43210. 


\section{INTRODUCTION}

There is growing evidence supporting the importance of relatively minor life events as important moderators of physical and psychological health; minor events appear to account for more of the variance in somatic and psychological symptoms than major life events (DeLongis et al., 1982; Kanner et al., 1981), even after controlling for initial psychological distress (Monroe, 1983). Recent research suggests that one critical mediating link between both major and minor stressful events and physical health may be the immune response, the body's defense against infectious and malignant disease.

Research from our laboratory has focused on the impact of relatively commonplace events on immunity. We have found significant changes in a number of different facets of the cellular immune response, in conjunction with relatively mild stressful events such as examinations. For example, we found a significant decrease in natural killer (NK)-cell activity in medical-student blood samples obtained during examinations, in comparison to baseline samples obtained 1 month earlier. Moreover, lonelier students had significantly poorer NK-cell activity (Kiecolt-Glaser et al., 1984a). These data may have important implications for health, since recent evidence strongly suggests an association between cancer incidence and NK-cell activity in humans (Strayer et al., 1984). Consistent with this, data of Levy et al. (1984) suggest that psychological factors are related to NK-cell activity and prognosis in women with breast cancer.

Other immune functions were also affected in this medical-student population; there were significantly higher antibody titers to three herpesviruses, Epstein-Barr virus (EBV), herpes simplex virus (HSV), and cytomegalovirus (CMV), in blood samples obtained from medical students during final examinations, in comparison to samples obtained after their return from summer vacation (Glaser et al., 1985). Higher antibody titers suggest less control over latent virus by the cellular immune response, while reestablishment of control over virus replication and latency is ultimately followed by a concomitant drop in antibody titers (Glaser and GottliebStematsky, 1982).

Based on these data and others (Kiecolt-Glaser and Greenburg, 1984; Kiecolt-Glaser et al., 1984b,c), we reasoned that interventions which reduced distress and/or loneliness might enhance cellular immunity. In a subsequent study, 45 geriatric residents of independent living facilities were randomly assigned to one of three protocols: (1) progressive relaxation training, (2) social contact, or (3) no contact. Subjects in the relaxation and socialcontact conditions were seen individually three times a week for 1 month. At the end of the intervention period, the relaxation group showed a significant increase in NK-cell activity and a significant decrease in antibody levels to HSV with a concomitant decrease in self-reported distress, in contrast to nonsignificant changes in the other two groups. Only the decrease in HSV 
antibody titers persisted at the 1-month follow-up, with little relaxation practice reported by subjects past the end of the intervention (Kiecolt-Glaser et al., 1985a).

In this study, 34 first-year medical-student volunteers had blood drawn twice, with the first (baseline) draw occurring 1 month before examinations and the second during examinations. Half of the subjects were randomly assigned to a hypnotic/relaxation group which met in the interval between bleeds. Subjects provided self-report data each time blood was drawn.

The study was designed to meet four objectives. The investigation of possible changes in the percentages of helper/inducer and suppressor/cytotoxic $\mathrm{T}$ lymphocytes and their ratio was of primary interest for this study, given previous data from both our laboratory and others documenting the impact of acute stressors on cellular immunity. Significant stress-related changes in the percentages of helper/inducer and suppressor/cytotoxic cells could have important consequences for health. Large reductions in the percentage of helper/inducer cells can produce immunodeficiency, while severe disturbances in the percentage of suppressor/cytotoxic cells are associated with autoimmune disorders (Reinherz and Schlossman, 1980).

Also of interest was the continued exploration of the effects of relaxation on immunity. We were particularly interested in testing the hypothesis that relaxation would buffer stress-related changes in cellular immunity, with the magnitude of the relationship dependent on the frequency of relaxation practice.

Nutritional measures were included to provide information on possible changes in nutritional status. There are well-documented impairments in various aspects of immunity found in undernourished individuals, and moderate to severe protein-caloric malnutrition is associated with increased frequency and severity of infection (Chandra, 1977). Since appetite and sleep disturbances are found more frequently in distressed populations, nutritional markers were included to assess the possibility that any changes in immunity simply reflected underlying nutritional changes. Three plasma protein markers were used, total iron-binding protein (TIBC), albumin, and transferrin.

Finally, NK-cell activity was assayed, in an attempt to replicate previously described stress-related changes (Kiecolt-Glaser et al., 1984a). The possible moderation of stress-related changes in this parameter by relaxation was also of interest.

\section{METHOD}

\section{Subjects and Timing of Samples}

The subjects were 35 first-year medical students in The Ohio State University College of Medicine who volunteered for a research project on 
stress and the immune response. One man did not return for the second blood draw. The average age of the remaining 22 men and 12 women was 23.5 years.

In the memorandum which described the study and solicited volunteers, the students were told that half of the group would be assigned to a hypnotic/relaxation group which would meet during lunch hours; volunteers were asked to be willing in principle to attend at least five sessions in the 2.5 weeks before the second blood draw, with the option of discontinuing at any time they wished. They were also told that those subjects who were not assigned to the relaxation group would have the same opportunity the following month. The only other inducement for participation was confidential individual and group feedback on changes in their immune response.

The first blood sample was drawn 1 month before examinations in midNovember, 1 month after the first examination series. The second blood sample was obtained on the final day of the 3-day mid-December examination period.

\section{Self-Report Measures}

The Brief Symptom Inventory (BSI; Derogatis and Spencer, 1982), administered both times blood was drawn, provided information on changes in global distress, as well as nine symptom dimensions. Subjects were asked to rate the amount of distress in the last 2 weeks which was associated with each of the 53 items from 0 (not at all) to 4 (extremely). The BSI also provided information on psychological symptomatology which might have contraindicated participation in the relaxation group, e.g., paranoid or psychotic symptomatology; no subject reported symptoms which made such participation inadvisable.

The brief state portion of the loneliness scale developed by Shaver et al.(1984) was administered at both sample points in order to provide information on changes in loneliness between the relaxation and the no-treatment groups. These data were of interest because of the possibility that the intervention might produce changes in loneliness as a result of potentially increased interpersonal contact for the experimental subjects.

The Shaver et al., (1984) state loneliness scale was created by combining eight items from the UCLA Loneliness Scale (Russell et al., 1980) and three items from the NYU Loneliness Scale (Rubenstein and Shaver, 1980). Both of these scales have adequate reliability and validity, which were established through a number of studies (e.g., Russell, 1982). The resulting state loneliness scale has coefficient alphas between 0.85 and 0.90 across various samples (Shaver et al., 1984), correlates significantly with the UCLA Loneliness Scale, and shows the expected changes when used with undergraduates during the transition into college. 
At the baseline sample point in November, subjects were asked to describe any chronic health problems. They were also asked the type and frequency of any regular self-relaxation practice (meditation, self-hypnosis, yoga, etc.).

On both occasions when blood was drawn, subjects were asked to describe any acute health problems in the last month, medications taken in the last 2 weeks, and caffeine intake in the last $48 \mathrm{hr}$. They were also asked to specify their present weight, and the amount of weight change, if any, during the last two weeks.

Questions added only at the second sample point included the number of times subjects had practiced any type of relaxation in the last month (outside of group practice), the amount of sleep in the last $72 \mathrm{hr}$ compared to normal requirements, the number of hours of vigorous physical activity in the last month, the quality of sleep in the last month, and any recent major life changes.

Two methods were used to evaluate the possibility that this volunteer subject sample might differ from their classmates in some important dimension(s), e.g., poorer students might volunteer in disproportionate numbers because of concerns about the possible physiological consequences of academic stress. The informed consent form included permission to check grades, so that the academic performance of participants could be compared with the nonparticipants (for whom grades were available without identifying information). In addition, all first-year medical students had taken the Sixteen Personality Factor Test (16PF) during orientation 2 months previous$l y$, and the scores of participants were compared to those of nonparticipants.

\section{Hypnotic/Relaxation Group}

The first session, attended by all assigned subjects, provided an overview of hypnosis and its similarities to other forms of relaxation, as well as an introductory group induction. The format of the remaining sessions was quite similar, since it was anticipated that attendance would vary across the 10 possible sessions. Each session began with the same standard deepening exercises. The middle portion of the session was varied and included selfhypnosis, progressive relaxation, autogenic training, and various imagery exercises. Suggestions made near the end of each session included greater relaxation throughout the day, enhanced comprehension and retention of academic material, and improved study habits. The subjects were strongly encouraged to practice relaxation outside of the group sessions. All of the group sessions were led by a clinical psychologist with substantial prior experience in various forms of relaxation training. 
At the end of each session, students rated the degree of relaxation achieved during the session from 1 (none) to 9 (completely relaxed); they were also asked for feedback on the session. The feedback sheets included a space for their subject number, thus providing a record of attendance and associated relaxation.

The group was designed to introduce the subjects to a number of different kinds of relaxation exercises, so that they might find the method(s) which best suited their own needs. The hypnotic format was chosen because the medical students were most familiar with it, and it was therefore most likely to elicit volunteers. No single relaxation technique was promoted to the exclusion of others, since the literature does not suggest that any one form of relaxation produces more reliable physiological effects than any other (e.g., Benson et al., 1978; Edmonston, 1981; English and Baker, 1983; Lehrer et al., 1980). Discussion during the relaxation sessions emphasized the commonalities among the various relaxation exercises. Sessions were 35-45 min in length.

\section{T-Lymphocyte Subset Assay}

The percentage of helper/inducer T cells, suppressor/cytotoxic $\mathrm{T}$ cells, and helper/suppressor-cell ratios were determined using the monoclonal antibodies OKT-4 and OKT-8, respectively (Ortho), as previously described (Moll et al., 1982).

Briefly, lymphocytes isolated on Hypaque-Ficoll gradients were washed with trypsin diluent, then resuspended in complete RPMI 1640 medium supplemented with $20 \%$ fetal bovine serum. Monocytes were removed by placing the cell suspensions in plastic tissue culture flasks and incubating at $37^{\circ} \mathrm{C}$ in a $\mathrm{CO}_{2}$ incubator for $1-3 \mathrm{hr}$. This adsorption was performed in order to reduce cell clumping and, therefore, to increase the accuracy of the counts. The nonadeherent cells were washed off and used to determine the percentage of T-cell subsets. Lymphocytes $\left(10^{6}\right)$ were incubated in $0.01 \mathrm{ml}$ of either OKT -4 or OKT-8 monoclonal antibody for $30 \mathrm{~min}$ on ice. Cells were washed with cold RPMI 1640 medium, resuspended in goat anti-mouse IgG conjugated to fluorescein isothiocyanate (Cappel Laboratories), and incubated for an additional $30 \mathrm{~min}$ on ice. The cells were washed and assayed, using an Ortho System 50 fluorescence-activated cell sorter (FACS). The normal range for OKT-4 (helper/inducer)-positive cells is approximately 33 to $53 \%$, and the normal range for OKT-8 (suppressor/cytotoxic)-positive cells is 11 to $30 \%$. The normal range for OKT-4/OKT-8 cell ratios is $1.1 .-3.5$. 


\section{NK-Cell Assay}

A microtiter chromium-51 release cytotoxicity assay was used to determine NK-cell activity, as previously described (Kiecolt-Glaser et al., 1984c). Briefly, mononuclear cells were obtained by Ficoll-Hypaque separation of whole blood. The target cells used in the assay were K-562 cells, a myeloid cell line.

Triplicate $(0.1-\mathrm{ml})$ aliquots of lymphocyte and labeled target-cell suspensions were placed in wells of 96-well plates (Limbro, Conn) resulting in effector- to target-cell ratios of 40:1, 20:1, and 10:1. In addition, triplicate wells with target cells and medium only and with target cells and detergent ( $1 \%$ socium dodecyl sulfate) were prepared in order to determine spontaneously released radioactivity and maximal lysis. Supernates were counted in a Beckman 9000 gamma counter. Results are reported as the percentage lysis using the formula

$$
\% \text { lysis }=\frac{\text { experimental } \mathrm{cpm}-\text { spontaneous release } \mathrm{cpm}}{\text { maximal } \mathrm{cpm}-\text { spontaneous release }} \times 100
$$

Using this procedure for the measurement of NK-cell lysis, differences are expected among the three effector:target-cell ratios, with larger ratios producing more lysis. The $40: 1$ ratio is the most sensitive, and the 10:1 the least, based on the larger supply of effector cells in the former.

\section{Nutritional Assays}

Protein assays provide better information on global nutritional status than those for carbohydrates and fats, since the former have varied nutritional building blocks, as well as very complex synthetic pathways. Different protein markers were used because of the differences in their half-lives; the half-life of albumin is 2 to 3 weeks, in comparison to 8 days for total ironbinding protein (TIBC) and transferrin. Transferrin and TIBC assays are different ways to measure the same protein.

The procedure use to measure albumin is an adaptation of the bromcresol green dye-binding method of Rodkey (1965), later modified by Doumas (1971). This procedure is recognized as a particularly good procedure as compared to other dye-binding techniques because of its specificity and freedom from interference.

To assay TIBC, ferric chloride was added to each plasma sample to saturate transferrin. The excess iron was removed with magnesium carbonate. 
After centrifugation the supernatant was measured for plasma iron by complexing the ferrous ions with ferrozine in a sodium acetate buffer solution. The absorbance of the violet-red complex was read at $560 \mathrm{~nm}$ in a spectrophotometer (Tietz, 1976).

Transferrin is an iron-transporting protein. The concentration in plasma is affected by the dietary intake of iron. Nutritionally deficient but calorierich diets are generally lacking in iron, and as a result, plasma iron levels tend to be low, and transferrin levels high. It has been shown that the estimation of transferrin levels may be used to assess the effectiveness of the total parenteral nutrition (Keyser, 1979).

A rate nephelometry procedure using a Beckman human immunoglobulin reagent kit and a Beckman immunochemistry analyzer system was used to analyze transferrin levels. Antibody to human transferrin was used in the assay, in which the peak rate signal caused by the antigen/antibody complex is proportional to the increase in light scatter which is read by the instrument (Buffone, 1980).

\section{RESULTS}

The data were analyzed using a repeated-measures analysis of variance design, with one between-subjects variable (group assignment) and one withinsubjects variable (change from the first to the second sample). Additional multiple regression analyses within the relaxation group were used to evaluate the hypothesis that the frequency of relaxation practice was a significant predictor of immunologic competence, after controlling for baseline levels.

\section{Baseline Comparisons and Information}

Baseline comparisons revealed no significant pretreatment differences between the intervention and the no-treatment group on the immunological or nutritional measures or in caffeine intake. Similarly, the groups did not differ significantly either in self-reported distress on the BSI scales or in state loneliness.

No subject reported any relaxation practice at baseline. No subject reported any acute or chronic health problems which might have a significant immunological component, aside from mild allergies. No subject reported taking any medication which had known immunological consequences.

\section{Self-Report Data}

The BSI data are presented in Table I. Post hoc analyses (Waller and Duncan, 1969) of the significant interactions showed nonsignificant change 
Table I. BSI Means and Standard Deviations for Relaxation and Control Groups at Baseline and During Ex-

\begin{tabular}{|c|c|c|}
\hline \multirow[b]{2}{*}{ BSI scale } & \multicolumn{2}{|c|}{ Group } \\
\hline & Relaxation & Control \\
\hline \multicolumn{3}{|l|}{ Somatization } \\
\hline Baseline & $49.26(6.67)$ & $49.93(8.36)$ \\
\hline Examination & $50.63(8.84)$ & $51.06(11.11)$ \\
\hline \multicolumn{3}{|c|}{ Obsessive-Compulsive } \\
\hline \multicolumn{3}{|c|}{ Symptomatology* } \\
\hline Baseline & $60.21(7.69)$ & $59.93(10.70)$ \\
\hline Examination & $59.53(9.75)$ & $65.20(11.18)$ \\
\hline \multicolumn{3}{|l|}{ Interpersonal } \\
\hline \multicolumn{3}{|l|}{ Sensitivity } \\
\hline Baseline & $56.63(12.23)$ & $58.87(10.96)$ \\
\hline Examination & $52.84(9.23)$ & $58.73(13.11)$ \\
\hline \multicolumn{3}{|l|}{ Depression } \\
\hline Baseline & $56.79(8.17)$ & $57.53(9.45)$ \\
\hline Examination & $55.21(7.93)$ & $55.73(11.94)$ \\
\hline \multicolumn{3}{|l|}{ Anxiety***** } \\
\hline Baseline & $57.32(9.26)$ & $55.60(10.66)$ \\
\hline Examination & $59.63(8.07)$ & $65.00(11.94)$ \\
\hline \multicolumn{3}{|l|}{ Hostility } \\
\hline Baseline & $52.89(9.43)$ & $54.60(7.50)$ \\
\hline Examination & $51.53(8.36)$ & $57.20(10.62)$ \\
\hline \multicolumn{3}{|l|}{ Phobic Anxiety } \\
\hline Baseline & $54.79(7.78)$ & $52.67(8.89)$ \\
\hline Examination & $50.21(6.01)$ & $52.00(9.20)$ \\
\hline \multicolumn{3}{|l|}{ Paranoia** } \\
\hline Baseline & $51.42(9.31)$ & $52.46(8.56)$ \\
\hline Examination & $48.00(7.97)$ & $50.53(10.95)$ \\
\hline \multicolumn{3}{|l|}{ Psychoticism } \\
\hline Baseline & $55.95(7.64)$ & $56.40(10.97)$ \\
\hline Examination & $53.16(7.67)$ & $56.33(12.43)$ \\
\hline \multicolumn{3}{|l|}{ Global Severity } \\
\hline \multicolumn{3}{|l|}{ Index* } \\
\hline Baseline & $57.42(7.89)$ & $57.07(10.42)$ \\
\hline Examination & $56.68(7.14)$ & $62.93(11.74)$ \\
\hline \multicolumn{3}{|l|}{ Positive Symptom } \\
\hline \multicolumn{3}{|l|}{ Total } \\
\hline Baseline & $56.47(6.52)$ & $56.07(9.53)$ \\
\hline Examination & $55.16(6.40)$ & $58.67(9.61)$ \\
\hline \multicolumn{3}{|l|}{ Positive Symptom } \\
\hline \multicolumn{3}{|l|}{ Distress Index } \\
\hline Baseline & $56.79(7.53)$ & $55.73(6.36)$ \\
\hline Examination & $53.00(9.06)$ & $58.53(9.26)$ \\
\hline
\end{tabular}

*Interaction between group and trial variables, $P<0.05$.

**Change over sample points, $P<0.05$.

${ }^{* * *}$ Change over sample points, $P<0.01$. 
within the relaxation group, compared to significant increases in anxiety ( $P$ $<0.01)$, in obsessive-compulsive symptomatology $(P<0.05)$, and in the global severity index $(P<0.05)$ in the no-intervention group.

There was a significant decrease in state loneliness from the first to the second bleed $[F(1,32)=13.22, P<0.001)$. The mean at baseline was 29.77 , compared to 26.02 during examinations. Neither the main effect for group membership nor the interaction between group membership and change across samples was significant $\left(F_{\mathrm{s}}<1\right)$.

One subject reported a 2 -lb weight loss in the 2 weeks before the baseline sample point, while three subjects reported weight gains of 2 to $4 \mathrm{lb}$. Four subjects reported weight losses of 1 to 4 pounds in the 2 weeks prior to examinations, while eight subjects reported weight gains of 1 to $6 \mathrm{lb}$.

The students were asked how many hours they had slept in the last 3 days before the second blood draw, in comparison to their normal sleep requirements. One subject reported sleeping more than usual in the $72 \mathrm{hr}$ before the second blood draw. Five subjects reported normal amounts of sleep, while the remaining 28 subjects reported an average deficit of $5.61 \mathrm{hr}(\mathrm{SD}=3.90)$. The size of the sleep deficit was not significantly correlated with any of the immunological measures taken during examinations.

There was not a significant difference in the quality of sleep between the intervention and the no-treatment groups, and they did not differ in the size of any sleep deficits $(F \mathrm{~s}<1)$. The number of hours of vigorous physical activity in the previous 3 weeks also failed to distinguish significantly between groups $(F<1)$, with a group mean of $6.00(\mathrm{SD}=4.21)$.

Caffeine usage in the $48 \mathrm{hr}$ before the blood draw increased significantly from the first to the second sample $[F(1,32)=4.89, P<0.05]$ but did not differ as a function of group membership or the interaction between the independent variables $\left(F_{\mathrm{S}}<1\right)$. The mean intake (equivalent to the number of cups of coffee) increased from 4.45 to 6.15. Caffeine intake was not significantly correlated with any of the immunological measures on either the first or the second sample, however.

In order to evaluate the effects of the relaxation intervention on academic performance, additional comparisons were made within the experimental group using the mean standard scores (across three disciplines) on the first and second tests in a $2 \times 2$ repeated-measures analysis of variance. There were no significant differences as a function of group membership ( $F$ $<1$ ), change from the first to the second test $(F<1)$, or the interaction between group membership and change from the first to the second test $[F(1$, 32) $=1.80]$.

The academic performances of participants and nonparticipants were not significantly different. The participants' mean standard score (across three disciplines) on the first examination did not differ from that of students who did not participate in this research project $(F<1)$. 
The scores of participants and nonparticipants were compared on each of the 16PF standard scales. There were no significant differences as a function of experimental participation.

\section{Immunological Data}

The percentage of helper/inducer cells decreased significantly in the examination sample compared to the baseline sample $[F(1,29)=10.27, P<$ 0.003 , as shown on the left side of Fig. 1. There was not a significant main effect as a function of group membership $(F<1)$, and the interaction between group membership and change over time did not reach significance $[F(1$, 29) $=3.40]$.

The percentage of suppressor/cytotoxic cells did not change significantly $[F(1,29)=3.38]$. The percentage of suppressor cells was $20 \%$ at baseline and $13.7 \%$ during examinations. There were no significant effects as a function of group membership $(F<1)$ or the interaction between group membership and change over trials $[F(1,29)=1.79]$.

The helper/suppressor-cell ratio decreased significantly from the first to the second sample $[F(1,29)=5.57, P<0.03]$, as shown in the right side of Fig. 1. There were no significant effects attributable to either group membership or the interaction between the two independent variables ( $F \mathrm{~s}$ $<1$ ). The normal ranges for the percentages of helper and suppressor cells are important in this context. Using these monoclonals (OKT-4 and OKT-8), the normal percentage of helper cells is from 34 to $54 \%$. The normal range for suppressor cells is 20 to $37 \%$, and the normal range for the helper/suppressor ratio is 1.1 to 3.7 .

After obtaining the low values for the medical students at the first sample point, additional assays were made using blood from 11 university staff
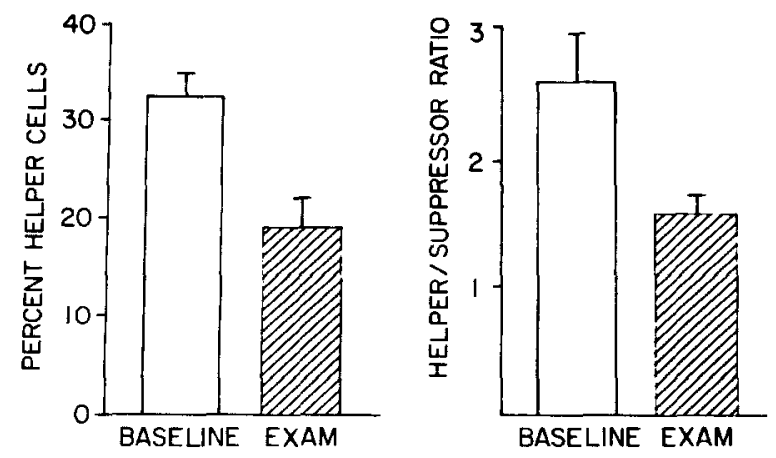

Fig. 1. Means ( \pm SE) at baseline and during examinations for the percentage of helper cells (left) and the helper/suppressor-cell ratio (right). 


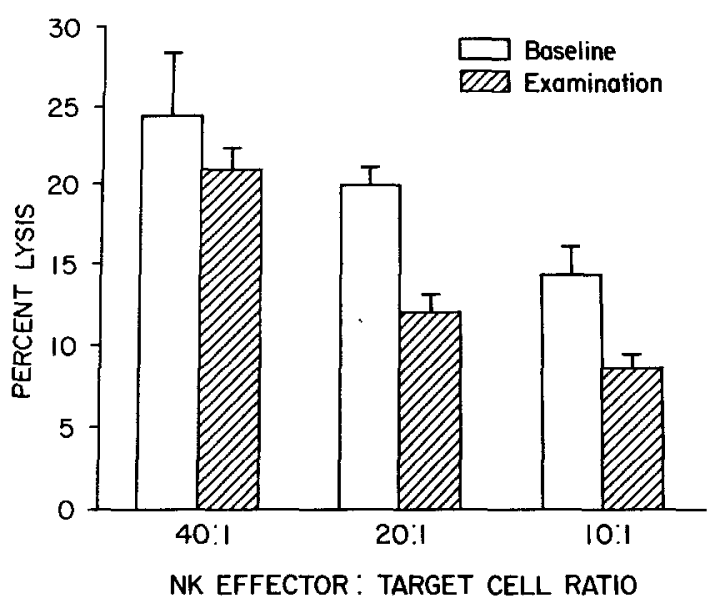

Fig. 2. Means ( $\pm S E$ ) for the three NK-cell effector- to targetcell ratios at baseline and during examiations.

members to assess the possibility that the low values reflected artifacts in the laboratory technique and/or in the monoclonal stock. These assays were run by the same technicians, and the monoclonal antibodies came from the same stock. The percentages of helper and suppressor cells from these subjects were well within normal limits, a finding not consistent with a laboratoryinduced artifact(s). The very low values found in medical-student samples during examinations compared to their already low baseline values further raised the possibility of stress-related impairments at baseline.

The NK-cell analysis included the three effector- to target-cell ratios as an additional variable. There was a significant decrease in NK-cell lysis of target cells as shown in Fig. $2[F(1,32)=11.07, P<0.003]$. There was also the expected significant main effect for differences among the three NK effector- to target-cell ratios, $[F(2,64)=45.05, P<0.0001]$. There was not a significant main effect attributable to group assignment, and the interaction between change over trials and group membership was not significant $\left(F_{\mathrm{s}}<1\right)$.

Multiple regression analyses were used to evaluate the hypothesis that the frequency of relaxation practice was a significant moderator variable in the stress-related immunological changes within the relaxation group; no subject in the no-treatment group reported any relaxation practice. There were large differences in the frequency of relaxation practice within the group; the sum of group attendance and home practice sessions ranged from 5 to 50 , with a mean of 12.07 and a standard deviation of 7.19. The frequency of relaxation practice was a significant predictor of the precentage of helper/inducer cells in the examination period after correcting for baseline 
Table II. Regression Analysis for Relaxation Frequency and Immunocompetence

\begin{tabular}{lcccc}
\hline $\begin{array}{l}\text { Dependent measures } \\
\text { (values during } \\
\text { examinations) }\end{array}$ & $\begin{array}{c}R^{2} \text { (Step 1 with } \\
\text { baseline only) }\end{array}$ & $\begin{array}{c}R^{2} \text { (Step 2 with } \\
\text { baseline and } \\
\text { relaxation } \\
\text { frequency) }\end{array}$ & $R^{2}$ change & $\begin{array}{c}\text { Simple } \\
\text { correlation }\end{array}$ \\
\hline $\begin{array}{l}\text { Helper/inducer } \\
\quad \text { cells (\%) }\end{array}$ & 0.05 & 0.43 & $0.38^{*}$ & 0.64 \\
$\begin{array}{l}\text { Suppressor/cytotoxic } \\
\text { cells (\%) }\end{array}$ & 0.03 & 0.18 & 0.15 & 0.34 \\
$\begin{array}{l}\text { Helper/suppressor-cell } \\
\text { ratio }\end{array}$ & 0.03 & 0.16 & 0.13 & 0.33 \\
$\begin{array}{l}\text { NK activity } \\
\quad 40: 1 \text { ratio }\end{array}$ & 0.48 & 0.58 & 0.10 & 0.28 \\
$20: 1$ ratio & 0.25 & 0.26 & 0.01 & 0.23 \\
$\quad 10: 1$ ratio & 0.24 & 0.31 & 0.07 & 0.38 \\
\hline$* P<0.01$. & & & &
\end{tabular}

levels; more frequent practice was clearly associated with higher helper/inducer-cell percentages, as shown in Table II. In contrast, the frequency of practice was not a significant predictor of the NK-cell activity.

\section{Nutritional Data}

Nutritional data are shown in Table III. Neither albumin nor TIBC plasma levels showed significant changes over time, and neither appeared to be affected by the relaxation intervention, with all $F_{\mathrm{S}}<1$. Plasma transferrin levels, in contrast, decreased significantly from the first to the second sample $[F(1,30)=8.89, P<0.01]$, although the second sample was still well within normal limits. There was not a significant difference between the two groups, nor was the interaction significant $(F \mathrm{~s}<1)$.

\section{DISCUSSION}

Significant declines were found in the percentage of helper/inducer cells, helper/suppressor-cell ratios, and NK-cell activity in the examination sam-

Table III. Normal Ranges, Means, and Standard Deviations for Plasma Protein Markers at Baseline and During Examinations

\begin{tabular}{lccc}
\hline & Albumin & TIBC & Transferrin \\
\hline Normal range & $3.8-5.1$ & $250-460$ & $178-410$ \\
Baseline & $4.90(0.34)$ & $363.33(60.48)$ & $346.57(53.61)$ \\
Examination & $4.91(0.24)$ & $370.40(21.27)$ & $318.73(50.49)$ \\
\hline
\end{tabular}


ple, compared to the baseline sample. The significant decrease in the percentage of helper/inducer cells and in the helper/suppressor ratio may have important implications for other aspects of the immune response. Both helper/inducer and suppressor/cytotoxic cells perform extremely critical regulatory functions for the immune response (Reinherz and Schlossman, 1980). Helper/inducer cells have an inducer function in the B-lymphocyte proliferation and differentiation sequence which is necessary for the synthesis of immunoglobulins; immunoglobulins provide a critical defense against infectious agents. The optimal development of cytotoxicity in suppressor/cytotoxic cells requires the presence of helper/inducer cells. Helper/inducer cells also play an inducer role in the interactions between $T$ lymphocytes and macrophages. Therefore, if helper/inducer-cell function is disrupted, immunodeficiency may result (Reinherz and Schlossman, 1980).

The finding that the frequency of relaxation practice was a significant predictor of helper/inducer-cell percentages in the second sample suggests that it may be possible to affect helper/inducer-cell percentages through common stress-reduction interventions. While further work is needed to confirm these data, such effects may have important clinical implications for some types of immunodeficient conditions.

The NK-cell data confirm our previous demonstration of stress-related changes in medical students. The absence of a significant relationship between the frequency of relaxation practice and NK-cell activity have been reported in mice exposed to various physical stresses, with such declines occurring within 24 to $48 \mathrm{hr}$ of stressor exposure (Aarstad et al., 1983; Herberman, 1982). In contrast, similarly rapid changes of that magnitude in the percentage of helper/inducer cells are unlikely. Thus, by the end of the 3-day examination period, any moderating effects in NK-cell activity attributable to relaxation may have been overshadowed by the acute stress of examinations.

While plasma transferrin levels declined significantly in this wellnourished population for unknown reasons, the final values were still well within the normal range, as were those for albumin and TIBC. Since TIBC measures the same protein as transferrin, it is unlikely that the decrease in transferrin indicates nutritional deprivation. These data suggest that the observed changes in cellular immunocompetence were not induced by poor nutrition. The minor changes in sleep also appear unrelated to the large immunological changes.

The selection of medical students is based in large part on their ability to reliably produce excellent examination scores. Despite their repeated successful performances in this situation, we still find consistent and significant changes in cellular immunity, both in these data and in our previous research with this population (Glaser et al., 1985; Kiecolt-Glaser et al., 1984a,c). It 
is not known whether this lack of adaptation occurs with repeated exposure to commonplace stressors in other populations; it provides an important question for future investigations, since it could have a significant long-term impact on health.

Neither the medical students in this study nor the geriatric subjects in our previous study (Kiecolt-Glaser et al., 1985a) were members of clinical populations seeking treatment for stress-related disorders. Since the subjects were not, as a group, significantly distressed or otherwise symptomatic before the intervention, their level of involvement and incentive for intensive practice may have been less than those found in many clinical populations; moreover, brief training in progressive relaxation is frequently not associated with significant autonomic changes among less anxious subjects (Lehrer $e t$ al., 1980). Therefore, these data may understate the magnitude of immunological change which is possible in more distressed populations.

These helper/inducer T-lymphocyte relaxation data have important clinical implications. Added to the previous study using a geriatric population (Kiecolt-Glaser et al., 1985a), these data provide further evidence that relaxation may be able to enhance at least some components of cellular immunity and, thus, perhaps ultimately might be useful in influencing the incidence and course of disease. Relaxation has already been shown to have a number of positive physiological effects, including recent data which demonstrate its impact on glucose tolerance in non-insulin-dependent diabetes (Surwit and Feinglos, 1983).

The medical-student and geriatric relaxation data provide new evidence for central nervous system medication of immune function. There are data suggesting that acute stress is immunosuppressive (e.g., Ader, 1981; Coe et al., 1985) and may be associated with important dysfunctions at the molecular level in DNA repair (Kiecolt-Glaser et al., 1985b). In contrast, it appears that relaxation may enhance immunity and provide a valuable "buffer" for at least some immunologic functions during more stressful times. Consistent with this, there has been considerable anecdotal and theoretical speculation concerning the possible enhancement of health through the elicitation of positive emotions (e.g., Cousins, 1976; Lazarus, 1982). It appears that such speculation may have some preliminary empirical support.

\section{ACKNOWLEDGMENTS}

We thank Allison Post and Carol Chung for laboratory assistance and Marta Berger, Daniel Georges, Perry Nystrom, and Tamara Wood for experimental assistance. We also wish to thank Angie Grieshop, Connie Gillam, 
Carolyn Pittenger, Kathy Reger, Patty Warren, Tim McManamon, and Steve Noel for drawing blood.

We are very grateful to our subjects, who began their first year of medical school in 1983 at The Ohio State University. This project would not have been possible without their enthusiastic participation.

\section{REFERENCES}

Aarstad, H. J., Gaudernack, G., and Seljelid, R. (1983). Stress causes reduced NK activity in mice. Scand. J. Immunol. 18: 461-464.

Ader, R. (ed.). (1981) Psychoneuroimmunology, Academic Press, New York.

Benson, H., Greenwood, M. M., and Klemchuck, H. (1975). The relaxation response: Psychophysiological aspects and clinical applications. Int. J. Psychiat. Med. 6: 87-98.

Benson, H., Frankel, F. H., Apfel, R., Danields, M. D., Schniewind, H. E., Nemiah, J. C., Sifneos, P. E., Crassweller, K. D., Greenwood, M. M., Kotch, J. B., Arns, P. A., and Rosner, B. (1978). Treatment of anxiety: A comparison of the usefulness of self-hypnosis and a meditation relaxation technique. Psychother. Psychosom. 30: 229-242.

Buffone, G. J. (1980). Transferrin, ICS-14, Beckman Instruments, Fullerton, Calif.

Chandra, R. K., and Newberne, P. M. (1977). Nutrition, immunity and infection. In Mechanisms of Interactions, Plenum Press, New York, pp. 235-248.

Coe, C. L., Weiner, S. G., Rosenberg, L. T., and Levine, S. (1985). Endocrine and immune responses to separation and maternal loss in nonhuman primates. In Reite, M., and Field, T. (eds.), The Biology of Social Attachment, Academic Press, New York, (in press).

Cousins, N. (1976). Anatomy of an illness (as perceived by the patient). New Engl. J. Med. 295: 1458-1467.

DeLongis, A., Coyne, J. C., Dakof, G., Folkman, S., and Lazarus, R. S., (1982). Relationship of daily hassles, uplifts, and major life events to health status. Health Psychol. 1: 119-136.

Derogatis, L. R., and Spencer, P. M. (1982). The Brief Symptom Inventory (BSI): Administration, Scoring, and Procedures Manual, $I$, Clinical Psychometric Research, Baltimore, Md.

Doumas, B. T., Watson, W. A., and Biggs, H. G. (1971). Albumin and the measurement of serum albumin with bromcresol green. Clin. Chim. Acta 31: 87-96.

Edmonston, W. E. (1981). Hypnosis and Relaxation, John Wiley, New York.

English, E. H., and Baker, T. B. (1983). Relaxation training and cardiovascular response to experimental stressors. Health Psychol. 2: 239-259.

Glaser, R., and Gottlieb-Stematsky, T. (eds.) (1982). Human Herpesvirus Infections: Clinical Aspects, Marcel Dekker, New York.

Glaser, R., Kiecolt-Glaser, J. K., George, J. M., Speicher, C. E., and Holliday, J. E. (1985). Stress, loneliness, and herpesvirus latency. J. Behav. Med. 8: 249-260.

Herberman, R. B. (1982). Possible effects of central nervous system on natural killer (NK) cell activity. In Levy, S. M. (ed.), Biological Mediators of Health and Disease: Neoplasia, Elsevier, New York, pp, 235-248.

Kanner, A. D., Coyne, J. C., Schaefer, C., and Lazarus, R. S. (1981). Comparison of two modes of stress measurement: Daily hassles and uplifts versus major life events. J. Behav. Med. 4: 1-39.

Keyser, J. W. (1979). Human Plasma Proteins, John Wiley, New York.

Kiecolt-Glaser, J. K., Garner, W., Speicher, C., Penn, G. M., Holliday, J. E., and Glaser, R. (1984a). Psychosocial modifiers of immunocompetence in medical students. Psychosom. Med. 46: 7-14.

Kiecolt-Glaser, J. K., Glaser, R., Williger, D., Stout, J., Messick, G., Sheppard, S., Ricker, D., Romisher, S. C., Briner, W., Bonnell, G., and Donnerberg, R. (1985a). Psychosocial enhancement of immunocompetence in a geriatric population. Health Psychol. 4: 25-41.

Kiecolt-Glaser, J. K., and Greenberg, B. (1984). Social support as a moderator of the aftereffects of stress in female psychiatric inpatients. J. Abnorm. Psychol. 93: 192-199. 
Kiecolt-Glaser, J. K., Ricker, D., George, J., Messick, G., Speicher, C. E., Garner, W., and Glaser, R. (1984b). Urinary cortisol, cellular immunocompetency and loneliness in psychiatric inpatients. Psychosom. Med. 46: 15-24.

Kiecolt-Glaser, J. K., Speicher, C. E., Holliday, J. E., and Glaser, R. (1984c). Stress and the transformation of lymphocytes by Epstein-Barr virus. J. Behav. Med. 7: 1-12.

Kiecolt-Glaser, J. K., Stephens, R. E., Lipetz, P. D., Speicher, C. E., and Glaser, R. (1985b). Distress and DNA repair in human lymphocytes. J. Behav. Med. 8: 311-320.

Lazarus, R. S. (1982). Stress and coping as factors in health and illness. In Cohen, J., Cullen, J. W., and Martin, L. R. (eds.), Psychosocial Aspects of Cancer, Raven Press, New York, pp. 163-190.

Lehrer, P. M., Schoickett, S., Carrington, P., and Woolfolk, R. L. (1980). Psychophysiological and cognitive responses to stressful stimuli in subjects practicing progressive relaxation and clinically standardized meditation. Behav. Res. Ther. 18: 293-303.

Levy, S. M., Herberman, R. B., and Maluish, A. M. (1984). Behavioral and immunological risk factors in primary breast cancer. Paper presented at the annual meeting of the Society of Behavioral Medicine, Philadelphia, $\mathrm{Pa}$.

Moll, B., Emeson, E. E., Small, C. B., Friedland, G. H., Klein, R. S., and Spigland, I. (1982). Inverted ratio of inducer to suppressor T-lymphocyte subsets in drug abusers with opportunistic infections. Clin. Immunol. Immunopathol. 25: 17-423.

Monroe, S. M. (1983). Major and minor life events as predictors of psychological distress: Further issues and findings. J. Behav. Med. 6: 189-205.

Reinherz, E. L., and Schlossman, S. F. (1980). Current concepts in immunology: Regulation of the immune response-Inducer and suppressor T-lymphocyte subsets in human beings. N. Engl. J. Med. 303: 370-373.

Rodkey, F. L. (1965). Direct spectrophotometric determination of albumin in human serum. Clin. Chem. 11: 478-487.

Rubenstein, C., and Shaver P. (1982). The experience of loneliness. In Peplau, L. A., and Perlman, D. (eds.), Loneliness: A Sourcebook of Current Research, Theory, and Therapy, Wiley Interscience, New York.

Russell, D. (1980). The revised UCLA Loneliness Scale: Concurrent and discriminant validity evidence. J. Personal. Soc. Psychol. 39: 472-480.

Russell, D. (1982). The measurement of loneliness. In Peplau, L.A., and Perlman, D. (eds.), Loneliness: A Sourcebook of Current Research, Theory and Therapy, John Wiley and Sons, New York.

Shaver, P., Furman, W., and Buhrmester, D. (1984). Aspects of a life transition: Network changes, social skills, and loneliness. In Duck, S., and Perlman, D. (eds.), The Sage Series in Personal Relationships, Vol. 1, Sage, London.

Strayer, D. R., Carter, W. A., Mayberry, S. D., Pequignot, E., and Brodsky, I. (1984). Low natural cytotoxicity of peripheral blood mononuclear cells in individuals with high familial incidences of cancer. Cancer Res. 44: 370-374.

Surwit, R. S., and Feinglos, M. N. (1983). The effects of relaxation on glucose tolerance in non-insulin-dependent diabetes. Diabetes Care 6: 176-179.

Tietz, N. W. (1976). The determination of iron and iron-binding capacity. Foundamentals of Clinical Chemistry, W. B. Saunders, Philadelphia, pp. 926-928.

Waller, R. A., and Duncan, D. B. (1969). A Bayes rule for the symmetric multiple comparisons problem. Am. Stat. Assoc. J. 64: 1483-1503. 